\title{
COMMENTARY
}

\section{Should we breathe quiet or noisy?}

\author{
Christian Putensen ${ }^{*}$ and Thomas Muders \\ See related research by Spieth et al., http://ccforum.com/content/17/5/R261
}

\begin{abstract}
External noise is introduced by computer-generated random levels of pressure assistance during noisy pressure support ventilation (PSV). In patients, noisy PSV was associated with higher tidal volume variability but not improved cardio-pulmonary function compared with conventional PSV. The potential role of noisy PSV in the management of critically ill patients requiring ventilatory support has to be explored further.
\end{abstract}

Although introduced as weaning techniques, modes providing mechanical support of spontaneous breathing have become standard in primary mechanical ventilator support in critically ill patients. In Critical Care, Spieth and colleagues [1] report for the first time the use of noisy pressure support ventilation (PSV) in patients with acute hypoxemic respiratory failure.

Normal breathing shows considerable variation in tidal volume $\left(\mathrm{V}_{\mathrm{T}}\right)$, flow rate, and respiratory rate, which is lost during mechanical ventilation (MV). In addition to elevation of intrathoracic and intrapulmonary pressures, MV causes a non-physiological uniform breathing pattern. Based on the concept that MV should mimic physiologically noisy breathing patterns, biologically variable or noisy MV was introduced, which attempted to mimic spontaneous breath-to-breath variability during volume-controlled MV [2]. Experimental and small clinical trials suggest that biologically variable or noisy MV may improve pulmonary gas exchange, compliance and dead space by preventing de-recruitment when compared to conventional MV [2,3]. These findings support the concept that alveolar recruitment achieved by large $\mathrm{V}_{\mathrm{T}}$ exceeds the de-recruitment by small $\mathrm{V}_{\mathrm{T}}$. Other mechanisms claimed to explain improved lung function during biologically variable or noisy MV include stochastic resonance [4], increased respiratory sinus

\footnotetext{
* Correspondence: putensen@uni-bonn.de

Department of Anesthesiology and Intensive Care Medicine, University of Bonn, 53105 Bonn, Germany
}

arrhythmia [5], endogenous surfactant release [6,7], and dynamic effects on the pressure-volume curve [7].

Nowadays, modes providing assisted support of spontaneous breathing should not only assure adequate gas exchange and unloading of the patient's work of breathing but should provide patient-ventilator synchrony, optimized diaphragmatic unloading, lung-protective ventilation, and the preservation of physiological respiratory patterns and variability. To accomplish all these tasks ventilatory assistance can no longer be constant but has to continuously adapt to changes in ventilatory demand and respiratory mechanics. To adapt to the continuously changing respiratory demand, pressure assistance is proportional to the instantaneous flow and volume, reflecting the inspiratory muscles' pressure during proportional assist ventilation (PAV) [8] or proportional to the electrical activity of the diaphragm during neurally adjusted ventilator assist (NAVA) [9]. Thus, PAV and NAVA try to amplify the patient's respiratory center output. Several experimental investigations and clinical trials in small groups of critically ill patients have demonstrated that PAV and NAVA, when compared to conventional PSV, enhance patient-ventilator interaction and synchrony, which translates into better comfort and sleep quality and preserves $V_{T}$ variability, which has been associated with improvements in gas exchange and lung mechanics $[10,11]$.

In patients with mechanically assisted spontaneous breathing, the noise can be introduced externally or can come directly from the respiratory center. In contrast to PAV and NAVA, which amplify the noise coming from the respiratory center, external noise is introduced by computer-generated random levels of pressure assistance during noisy PSV [12]. Experimental investigations in induced lung injury showed that noisy PSV, when compared with conventional PSV and pressure-controlled $\mathrm{MV}$, was associated with a significantly higher coefficient of variation of $\mathrm{V}_{\mathrm{T}}$ and airway pressure, and resulted in better pulmonary gas exchange, reduced alveolar edema in overall lung as well as reduced inflammation in the nondependent parts of the lungs [13]. In a porcine 
model with induced lung injury an external source of noise (noisy PSV) and noise derived from amplification of the respiratory center (PAV) improved gas exchange and produced higher $\mathrm{V}_{\mathrm{T}}$ variability, whereas the pulmonary inflammatory response and diffuse alveolar damage score did not differ when compared to conventional PSV lungs [14].

Spieth and colleagues [1] investigated the short-term effects of conventional and noisy PSV in patients with acute hypoxemic respiratory failure. Noisy PSV was associated with higher $\mathrm{V}_{\mathrm{T}}$ variability and a lower number of asynchrony events. In contrast to experimental findings, cardio-pulmonary function and spatial distribution of ventilation were comparable between conventional and noisy PSV [1]. During conventional and noisy PSV, however, $\mathrm{V}_{\mathrm{T}}$ significantly higher than $8 \mathrm{ml} / \mathrm{kg}$ predicted body weight was frequently noticed. By design noisy PSV applies $V_{T}$ as high as $16 \mathrm{ml} / \mathrm{kg}$ and as low as $1.6 \mathrm{ml} / \mathrm{kg}$ once every 20 to 30 minutes [12]. Although short-term experiments demonstrate that this mixture of ultra-protective and non-protective $\mathrm{V}_{\mathrm{T}}$ during noisy PSV does not add to lung injury based on histological examinations, long-term investigations have to clarify the relevance of periodic non-protective $V_{T}$ ventilation in critically ill patients.

\section{Conclusion}

The findings of Spieth and colleagues [1] are in line with the observation that, in patients with acute hypoxemic respiratory failure, PAV was associated with higher $V_{T}$ variability but did not improve cardio-pulmonary function when compared with conventional PSV [10]. Thus, application of an external source of noise with noisy PSV and amplification of the respiratory center-derived source of noise with PAV may both allow higher $\mathrm{V}_{\mathrm{T}}$ variability $[1,10]$. However, we have to question if higher $V_{T}$ variability improves outcome, reduces cost, decreases the frequency of complications, or simplifies patient management or care giving. Unfortunately, apart from experiments or small clinical trials showing some physiological or clinical benefits, noisy PSV must still show its real clinical benefits in large clinical trials before becoming a routine method of ventilation. Thus, noisy ventilation is clearly not something that should be currently adopted in either controlled or assisted MV.

\section{References}

1. Spieth PM, Güldner A, Huhle R, Beda A, Bluth T, Schreiter D, Ragaller M, Gottschlich B, Kiss T, Jaber S, Pelosi P, Koch T, Gama De Abreu M: Short-term effects of noisy pressure support ventilation in patients with acute hypoxemic respiratory failure. Crit Care 2013, 17:R261.

2. Lefevre GR, Kowalski SE, Girling LG, Thiessen DB, Mutch WA: Improved arterial oxygenation after oleic acid lung injury in the pig using a computer-controlled mechanical ventilator. Am J Respir Crit Care Med 1996, 154:1567-1572.

3. Kowalski S, McMullen MC, Girling LG, McCarthy BG: Biologically variable ventilation in patients with acute lung injury: a pilot study. Can J Anaesth 2013, 60:502-503.

4. Suki B, Alencar AM, Sujeer MK, Lutchen KR, Collins JJ, Andrade JS Jr, Ingenito EP, Zapperi S, Stanley HE: Life-support system benefits from noise. Nature 1998, 393:127-128.

5. Graham MR, Warrian RK, Girling LG, Doiron L, Lefevre GR, Cheang M, Mutch WA: Fractal or biologically variable delivery of cardioplegic solution prevents diastolic dysfunction after cardiopulmonary bypass. J Thorac Cardiovasc Surg 2002, 123:63-71.

6. Arold SP, Suki B, Alencar AM, Lutchen KR, Ingenito EP: Variable ventilation induces endogenous surfactant release in normal guinea pigs. Am J Physiol Lung Cell Mol Physiol 2003, 285:L370-L375.

7. Ma B, Suki B, Bates JH: Effects of recruitment/derecruitment dynamics on the efficacy of variable ventilation. J Appl Physiol (1985) 2011, 110:1319-1326.

8. Costa R, Spinazzola G, Cipriani F, Ferrone G, Festa O, Arcangeli A, Antonelli M, Proietti $\mathrm{R}$, Conti $\mathrm{G}$ : A physiologic comparison of proportional assist ventilation with load-adjustable gain factors $(\mathrm{PAV}+)$ versus pressure support ventilation (PSV). Intensive Care Med 2011, 37:1494-1500.

9. Sinderby C, Navalesi P, Beck J, Skrobik Y, Comtois N, Friberg S, Gottfried SB, Lindström $\mathrm{L}$ : Neural control of mechanical ventilation in respiratory failure. Nat Med 1999, 5:1433-1436.

10. Varelmann D, Wrigge $H$, Zinserling J, Muders T, Hering R, Putensen C: Proportional assist versus pressure support ventilation in patients with acute respiratory failure: cardiorespiratory responses to artificially increased ventilatory demand. Crit Care Med 2005, 33:1968-1975.

11. Coisel Y, Chanques G, Jung B, Constantin JM, Capdevila X, Matecki S, Grasso S, Jaber S: Neurally adjusted ventilatory assist in critically ill postoperative patients: a crossover randomized study. Anesthesiology 2010, 113:925-935.

12. Beda A, Spieth PM, Handzsuj T, Pelosi P, Carvalho NC, Koch E, Koch T, Gama De Abreu M: A novel adaptive control system for noisy pressurecontrolled ventilation: a numerical simulation and bench test study. Intensive Care Med 2010, 36:164-168.

13. Spieth PM, Carvalho AR, Güldner A, Kasper M, Schubert R, Carvalho NC, Beda A, Dassow C, Uhlig S, Koch T, Pelosi P, Gama De Abreu M: Pressure support improves oxygenation and lung protection compared to pressure-controlled ventilation and is further improved by random variation of pressure support. Crit Care Med 2011, 39:746-755.

14. Spieth PM, Güldner A, Beda A, Carvalho N, Nowack T, Krause A, Rentzsch I, Suchantke S, Thal SC, Engelhard K, Kasper M, Koch T, Pelosi P, de Abreu MG: Comparative effects of proportional assist and variable pressure support ventilation on lung function and damage in experimental lung injury. Crit Care Med 2012, 40:2654-2661.

$10.1186 / \mathrm{cc} 13762$

Cite this article as: Putensen and Muders: Should we breathe quiet or noisy?. Critical Care 2014, 18:116

\author{
Abbreviations \\ MV: Mechanical ventilation; NAVA: Neurally adjusted ventilator assist; \\ PAV: Proportional assist ventilation; PSV: Pressure support ventilation; \\ $V_{\mathrm{T}}$ : Tidal volume.
}

\section{Competing interests}

The authors declare that they have no competing interests. 